\title{
Universal-Aggregometer
}

Die B. Braun Melsungen AG bringt ein neues Universal-Aggregometer in den Handel.

Es dient zur Messung der spontanen Thrombozytenaggregation nach Breddin und der induzierten Plättchenaggregation nach Born.

Meßprinzip

Eine kleine Menge $(0,6 \mathrm{ml})$ plättchenreichen Plasmas rotiert direkt im Strahlengang eines Photometers in einer scheibenförmigen Küvette bei $37^{\circ} \mathrm{C}$. Die Änderungen der optischen Dichte durch die Aggregatbildung werden fortlaufend mittels Schreiber registriert. Entscheidend für die Auslösung der Aggregation ist der während der Rotation erfolgte Anstieg des Plasma-pH durch Austritt von $\mathrm{CO}_{2}$.

Das gesamte Meßsystem setzt sich zusammen aus der im Strahlengang des Photometers rotierenden Küvette, aus dem Photometer und dem Kompensationsschreiber, der den Aggregationsvorgang aufzeichnet. Bei der Messung der induzierten Aggregation wird in den Strahlengang des Photometers zusätzlich ein Adapter gesteckt, in dem sich das Meßröhrchen befindet; dafür entfällt die Scheibenküvette bei diesem Verfahren.

Das Universal-Aggregometer ist an Eppendorf-Photometer adaptierbar ohne großen Umbau.

\section{Technische Daten}

Drehzahl der Scheibenkuivette 20 Upm; Drehzahl des Magnetrührers 1000 Upm; Temperatur des Plasmas in beiden Küvetten $37^{\circ} \mathrm{C}$; Aufheizzeit des Plasmas in den Küvetten auf $37^{\circ} \mathrm{C}$ max. $15 \mathrm{~min}$; Scheibenküvette, Schichtdicke $8 \mathrm{~mm}$, Außendurchmesser $20 \mathrm{~mm}$, Material: durchsichtiger Kunststoff; Meßküvette für die induzierte Aggregation, Kunststoffröhrchen von $11 \mathrm{~mm}$ Außendurchmesser und $75 \mathrm{~mm}$ Länge aus durchsichtigem Kunststoff oder silikonisiertes Glasröhrchen; Blendendurchmesser $2 \mathrm{~mm}$; Filter $546 \mathrm{~nm}$.

(B. Braun Melsungen AG, Medizinisch-pharmazeutische Werke, D-3508 Melsungen, Postfach 110 und 120, Telefon 05661-711.)

\section{PERSONALIA}

\section{Basel}

Dr. B. Speck, Medizinische Universitätsklinik, habilitierte sich für Innere Medizin, speziell Hämatologie.

\section{Bern}

Prof. Dr. U. Bucher, Extraordinarius für Innere Medizin, speziell Hämatologie der Universität, wurde zum Ordinarius ad personam ernannt.

\section{Kiel}

Prof. Dr. L.-D. Leder, Pathologisches Institut der Universität, hat einen Ruf an die Freie Universität Berlin erhalten. 